$A R T I I C U L C O D E$ I $N$ VEESTIGACIÓ $N$ $\begin{array}{lllllllllllllllllll}C & I & E & N & T & I & F & I & C & A & Y\end{array}$

T E C N O L Ó G I C A

\title{
CiUdAd, SUBJETIVIDAD Y PLACER. LA SOCIALIZACIÓN HOMOSEXUAL MASCULINA EN VILLAVICENCIO1
}

\author{
CITY, SUBJECTIVITY AND PLEASURE. MALE HOMOSEXUAL \\ SOCIALIZATION IN VILLAVICENCIO
}

\section{Por: Jose Miguel Segura Gutiérrez*}

*Administrador Público de la Escuela Superior de Administración Pública-Medellín. Mención en Historia en la Universidad del en rio-Bogotá Espec á. Especialista en Gerencia Social por la Corporación Universitaria Minuto de DiosBogotá. Magister en Desarrollo Educativo y Social de la Universida Pedágic univion Pedagogica Nacionalfesor catedrático de la Universidad Cooperativa de Colombia (Campus Villavicencio) y Universidad de los Llanos (Villavicencio) Email: josemielseg mail josemielsegura gmail.com

1 Artículo de investigación. El presente documento, hizo parte de la propuesta de investigación desarrollada por el autor en la línea de investigación "Socialización política y construcción de subjetividades" (2015-2016), de la Maestría en Desarrollo Educativo y Social de la Universidad Pedagógica Nacional (Bogotá).
Recibido: 20 de febrero de 2017 - Aprobado: 27 de junio de 2017

\section{RESUMEN}

El artículo indaga por las diversas formas de socialización homosexual, ejecutadas por un grupo de varones en la ciudad de Villavicencio (Colombia) y su impacto en la constitución de la subjetividad sexual. Para ello, se entrecruzan algunas descripciones de la ciudad obtenidas mediante una amplia revisión bibliográfica, que sumadas a algunos relatos sobre la experiencia homosexual masculina vivida en la ciudad, permiten plantear un vínculo entre los diversos flujos existenciales, prácticas sexuales y modos de vida gestados por hombres homosexuales al interior del espacio citadino. La ciudad con sus instituciones y reglas sigue siendo el medio para ejercer poder sobre el cuerpo y los placeres de sus agregados, a través de un proceso dinámico, que transita entre la individuación singular y la modulación social.

Palabras clave: ciudad, homosexualidad, placer y subjetividad.

\section{ABSTRACT}

The article inquires the different forms of homosexual socialization carried out by a group of men in the city of Villavicencio (Colombia) and its impact on the constitution of sexual subjectivity. To this end, some descriptions of the city obtained through a large bibliographical review are interwoven, which, together with some stories about the male homosexual experience lived in the city, allow to establish a link between the various existential flows, sexual practices and lifestyles created by homosexual men into the urban space. The city with its institutions and rules continues to be the means to exert power over the body and the pleasures of its aggregates, through a dynamic process that transits between singular individuation and social modulation.

Keywords: city, homosexuality, pleasure and subjectivity.

\section{Introducción}

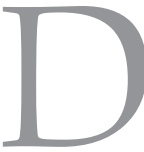

iscutir en torno a la relación existente entre la homosexualidad como expresión subjetiva de ser y estar en el mundo, con otras realidades sociales como la ciudad, constituye hoy en Colombia un productivo campo de estudio frente a la comprensión de la sexualidad. Ejemplo de ello, 
son los trabajos adelantados por Bustamante (2004, 2008), Gallego (2016), Gil (2013) y Segura $(2008,2014,2015)$ quienes desde sus respectivos campos disciplinares, buscan visibilizar la aplicación de dispositivos de poder, sobre el cuerpo y la subjetividad de aquellos sujetos, cuyas prácticas e identidades no se alinean a la heterosexualidad.

El homosexual al decir de Bustamante (2004), es un sujeto/objeto aparecido en el contexto del saber colombiano, a mediados de 1930. Pero que dada, la exacerbación actual del placer sexual, a través de la publicidad y los medios de comunicación, ha terminado por llamar de nuevo la atención, frente a cómo las vivencias de aquellos hombres cuyo cuerpo y sexualidad, se ha formado a partir del deseo por otros hombres, tensionan los marcos institucionales y acuerdos sociales establecidos por la ciudad, en detrimento de un proceso de socialización y constitución subjetiva, libre y espontánea para quienes abrazan dicha orientación sexual.

Con respecto a la configuración del homosexual masculino en la ciudad, se tiene que la "oferta" de otros cuerpos desplegados, a través de sus diferentes lugares, no dan descanso a la vista y sí precipitan la búsqueda de personas, mediante el acceso a portales de internet, www.manhunt.net, o uso de redes sociales, Grindr, que aunque en apariencia reducen la incertidumbre frente a ¿Quién me espera y aún no conozco? no logran avanzar, más allá de una noche de placer y gastos económicos derivados del preludio amatorio.

En torno a la homosexualidad y sus prácticas, esta ha sido vista desde la ciudad como una forma de sociabilidad vinculada al sexo y consumo de servicios de índole mercantil, que al articularse con el capital, no solo han restringido las posibles heterogeneidades en las formas y valores, que presentan los individuos homosexuales en el conjunto de interacciones sociales, sino además, a provocado que la emoción surgida a partir de las sensaciones visuales, termine en una liberación unívoca de la imaginativa sexual hacia el placer corporal.

Por ello, que al preguntar por ¿Cómo se dan los procesos de socialización y configuración subjetiva del homosexual masculino en la ciudad de Villavicencio? se visibilice, la experiencia de un sujeto (homosexual) dentro del binomio capital-vida que caracteriza a la ciudad, y los efectos que dicha relación tiene sobre las diversas formas de relacionamiento social, configuración subjetiva y búsqueda de placer ejecutadas por varones homosexuales en esta ciudad. 
De acuerdo con Segura (2008:156) "el modelo del sistema de interacción entre las identidades homosexuales y la ciudad, se halla esbozado a través de un ordenamiento social, en el cual no se acepta este tipo de prácticas, pero que sí permite las relaciones entre varones, siempre y cuando en ellas se produzca el control de unos sobre otros. Lo cual, evidencia la discriminación selectiva que realiza la ciudad, sobre el espectro posible de relaciones entre los individuos".

"[...] el homosexual es alguien cuya definición se deja a otros, alguien a quien se niega el acto de su propia definición con respecto a su sexualidad, alguien cuya autonegación es un requisito indispensable" (Butler, 2005:178). Esto incluso, cuando los procesos de construcción de las subjetividades homosexuales, parten de espacios de socialización —familia, escuela-en los que los individuos logran identificarse como homosexuales, pero sin las garantías para manifestar libremente su opción sexual. En palabras de Segura (2015:85) "[...] la ciudad, representa en sí misma la materialización de la hegemonía heterosexual, en pro del bienestar social de sus asociados dentro de ciertos acuerdos preestablecidos, pero que imprime penas y castigos para aquellos individuos que se mueven dentro de la clandestinidad de algunos de sus recovecos".

Esto en el entendido, que el conjunto de interrelaciones en que se ve envuelto y participa el individuo no solo afecta su vida personal, sino también su configuración como sujeto sexual. Al decir de Brigeiro et al (2012:8) “[...] uno de los más importantes avances en la discusión sobre la sexualidad aportado por los científicos sociales es haber conceptualizado que, lejos de poder ser comprendida como algo natural, la misma es permanentemente regulada por una serie de dispositivos legales, morales y sociales".

\section{Sobre el contexto estudiado}

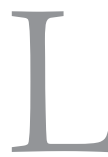

a ciudad de Villavicencio (Colombia), está ubicada territorialmente entre la cordillera oriental y los llanos, más específicamente en la franja denominada piedemonte, a la fecha cuenta con aproximadamente 484.429 habitantes (Dane, 2005), población que aumenta en fines de semana y temporada de vacaciones (Semana Santa, junio y diciembre). Lo anterior, en razón al carácter de destino turístico adquirido con la implementación de la política de seguridad democrática, adelanta por la administración Uribe Vélez (2002-2006 / 2006-2010). 
No obstante a eso, Villavicencio a la fecha se presenta como una ciudad cuya economía se ancla al sector servicios, pero matizada por una tradición cultural fragmentada, en razón a un proceso de colonización basado en el flujo migratorio surtido por la violencia política bipartidista y el ansia de dominar un paisaje de llanura.

Situación, que deja ver cómo aunque en Villavicencio se han dado algunas experiencias sociales vinculadas al tema de diversidad sexual (Segura,2014) y en su territorio se han establecido bares como Blue Martini, Candi bar, discotecas Zoggga club, saunas Club burlesque, además de centros comerciales como Unicentro ${ }^{2}$, Villacentro y Primavera, que sirven de plataforma para dinamizar tendencias y agenciar diversas prácticas socio-sexuales al interior de la ciudad. La problemática de las minorías sexuales sigue estando relacionada con las opciones de realización personal e integración social, que se ofrecen en la ciudad.

\section{Trayecto metodológico}

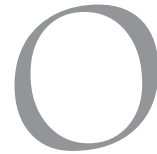

frecer una respuesta frente a icómo se dan los procesos de socialización y configuración subjetiva del homosexual masculino en la ciudad de Villavicencio? requirió en principio, fijar la atención ante lo inesperado que dicho espacio ofrece a los actores sociales, para que configuren, desde sus prácticas ciertas posibilidades de constitución subjetiva. Por ello, se seleccionó y mapeo un lugar de encuentro sexual (Figura 1) ubicado en pleno centro de Villavicencio y mediante seguimientos a distancia, marcó los recorridos y trayectos sobre los que avanzaron los actores involucrados en dicho encuentro (Figura 2).

Con respecto a la primera figura, el lugar fue seleccionado por la alta afluencia de público masculino de diverso ciclo generacional y posición socioeconómica en horas de la noche, la forma en que se ubican y distribuyen en el espacio, los recorridos que agencian y las formas en que establecen contacto con otros individuos. Lo cual, necesitó varias visitas al lugar.

Ahora bien, con relación a la forma de abordaje de los informantes en terreno, estuvo mediada por el ofrecimiento de algún comentario o bebida, que simulara un interés inicial, que luego de un tiempo y el diálogo desprevenido, consintió aflorara la confianza necesaria para avanzar en un periplo, que permitió dar cuenta, no solo de la ampliación del espacio de encuentro sexual -Plazoleta-, sino de la constitución y reconocimiento de un circuito ${ }^{3}$ del placer homosexual en el centro de Villavicencio.
2 De acuerdo a lo expresado por algunos de nuestros colaboradores, los nombres de los centros comerciales han sido resignificados, a partir de la identidad que expone el individuo-visitante y al uso que este hace del espacio comercial -Unigay, Vivagay y Villagay-. Tanto así, que durante la realización de esta investigación, fue posible observar como algunos jóvenes y adultos ocupan las unidades de baño de dichos centros comerciales, a la espera del ingreso de otros hombres, con los cuales puedan satisfacer su apetito sexual o proyectar sus fantasías. Incluso cuando saben de la disposición de cámaras de video instaladas en el lugar.

3 Entiendo por circuito la disposición de puntos convergentes entre sí, con entradas y salidas que facilitan el encuentro e interacción entre agentes. Para el caso, tiene que ver con cómo la configuración de la subjetividad homosexual masculina, encuentra en la ciudad y sus lugares un punto de arranque, para su desarrollo, pero que dada su adscripción a un régimen heterosexual, termina por objetivar a sus miembros, desde la ocupación de espacios para la visibilidad, y el cuestionamiento frente a lo que traerá la noche y cuáles serán sus desempeños, dentro de un contexto marcado por el dinero, el culto a la belleza y los usos que estos mismos sujetos hacen del cuerpo y el sexo. 


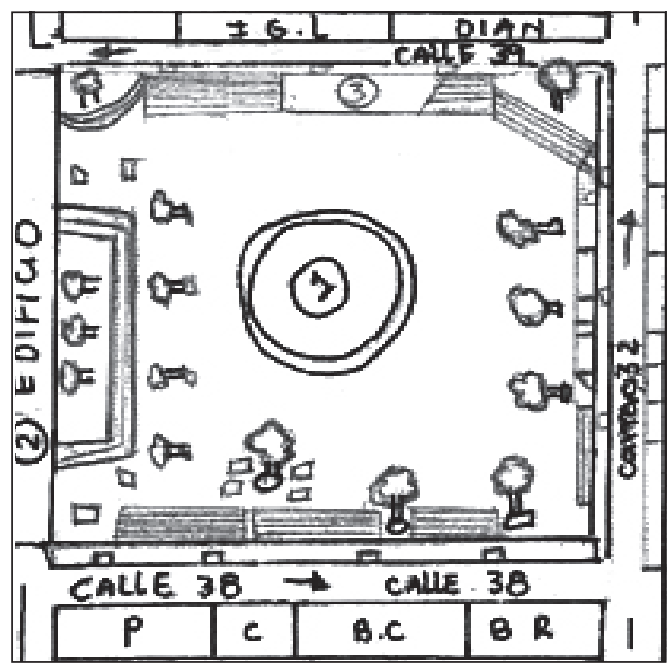

Figura 1. Plaza Los Libertadores

Fuente: Elaboración Propia (2015) 1-árbol 2-Gobernación del Meta 3-Fuente

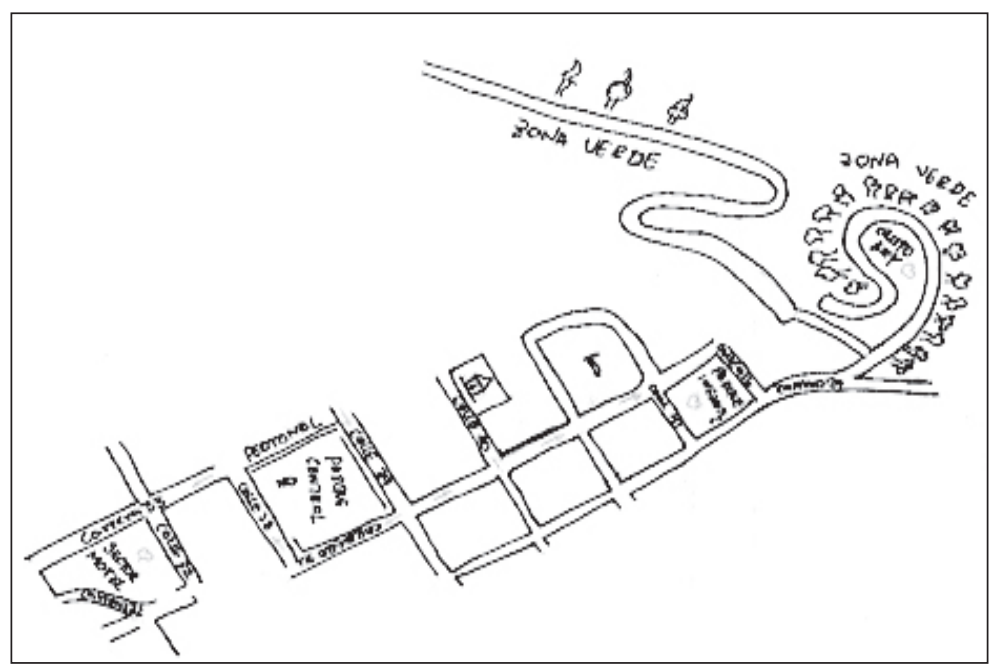

Figura 2. Tránsitos y recorridos del placer homosexual en el centro de Villavicencio Fuente: Elaboración Propia (2015)

Como segundo recurso, se consideró la selección de informantes desde un portal web www.manhunt.net, a los cuales se aproximó a través de un mensaje de chat generado por el investigador y en segundo término, como respuesta al guiño o comentario emitido por otro usuario. Abierto el espacio dialógico, este tuvo como fin informar a los cibernautas del objeto del estudio y la necesidad de contar con su consentimiento frente al registro inmediato o futuro de algunos fragmentos de sus relatos, los cuales iniciaron con la caracterización de los mismos, y el desarrollo, transformación y vivencia de su condición sexual en la ciudad.

Los participantes fueron dos estudiantes universitarios, y tres hombres adultos, escogidos por su conocimiento de la ciudad, y presentar aspectos diversos —origen, estrato socioeconómico, experiencia de vida—. Las edades de estos colaboradores están entre los 18 y 35 años y sus nombres fueron alterados, para mantener la confidencialidad.

\section{El capitalismo como modelo de gestión urbana}

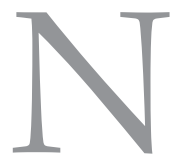

unca como hoy la ciudad en tanto constructo social ligado al territorio, había reafirmado su condición de espacio de interacción sociocultural e intercambio económico-comercial, como bajo el modelo capitalista. Es decir, por una forma de poder disciplinario que de acuerdo con Hardt y Negri (2000) gobierna la vida de las personas, a través de la estructuración de parametros y límites al pensamiento y 
la práctica, sancionando y prescribiendo los comportamientos normales y/o desviados.

Por eso, que al observar cómo al interior de la ciudad los colectivos humanos que la habitan han plegado su libertad, a un modelo de gestión frente a la forma de vivir en comunidad, cuenta según Hard y Negri (2000:25) que "la sociedad disciplinaria es aquella en la cual el comando social se construye a través de una red de dispositivos o aparatos que producen y regulan costumbres, hábitos y prácticas productivas".

El planteamiento del capitalismo en la ciudad, consiste en modelar al gobierno y reducir las posibilidades de producción de aquello que se requiere para ser libre, ya sea mediante el despliegue de algunas situaciones cuyo objeto es la (re)-producción de la vida con sus diferentes grados de libertad, o como posibilidad para que emerjan procedimientos de control y coacción, a esas mismas libertades. Como afirmará Foucault (2010:34): “Gobernar es siempre un difícil y versátil equilibrio, con conflictos y complementariedades, entre las técnicas que aseguran la coerción y los procesos a través de los cuales el "uno mismo" es construido y modificado por sí mismo".

Por ello, que al explorar, cómo un modo de vida en la mayoría de veces asociado a la ejecución de prácticas sexuales, genera distintas tensiones frente al ejercicio de autonomía dentro de marcos sociales preestablecidos, confirme que la subjetividad está modelada esencialmente desde el registro social que reconoce un cuerpo. Según Pacheco (2005:166) "La ciudad, como espacio de civilización, requiere normas específicas de comportamiento. Esas normas se refieren a la homogeneización de los movimientos corporales y la domesticación de los instintos".

Esto en razón, a que la sexualidad y el placer como aspectos claves en la conformación de las subjetividades, hoy se han transformado hacia una vivencia constitutiva de la vida de los individuos, que bajo el modelo capitalista termina por objetualizar su conocimiento y prácticas sexuales, como en mercancías. Tal y como se visualiza en el siguiente ejemplo:

\section{Campamento gay}

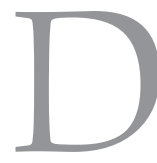

ebido al gran éxito de las 4 versiones anteriores, lanzamos el "5 encuentro llanero de amigos" esta vez enmarcado en el día del orgullo LGBTI, junio 27, 28, 29. Ven a nuestra finca del placer en un 
ambiente totalmente campestre y disfruta de nuestras grandes sorpresas: 3 tipos de alojamiento en las únicas y auténticas pesebreras VIP de Colombia, en carpas de camping y en habitaciones compartidas. Salón de los potrancos desbocados. Nuevo pasillo de las terneras huérfanas. Nuevo nido de las vacas muertas. Hamacas para becerras voladoras. Zona para lluvia dorada de toretes. Gran fiesta de espuma por el orgullo gay en la piscina. Fogata y canelazo bajo las estrellas de nuestro llano. Juegos erótico-sexuales. Caminata ecológica. Ven y disfruta de un fin de semana inigualable en el único retiro sexual gay de los llanos orientales. Fuente: www.manhun.net (Ingreso 24 de junio de 2015).

Recurso de investigación, que revela como en la ciudad se da una trama compleja de historias, tiempos y recorridos, que coexisten junto a otros modos de interacciones socio individuales, agenciados por el plano capital y la dinámica global, en que transitan actualmente los procesos sociales y de configuración subjetiva de quienes habitan la ciudad, pero que no logran así, excluirlos del engranaje económico-comercial, que esta guarda. De acuerdo con Pacheco (2005:70) "La ciudad actual contribuye a la conformación de subjetividades mundiales, no porque en sí pertenezca a circuitos planetarios sino porque coloca a los sujetos como vitrinas desde donde ven y son vistos".

En la ciudad, los homosexuales han emergido como un grupo social vinculado a lugares y colectivos, además de ser el producto de una socialización cuyos significados han estado asociados con la elección del objeto sexual, y la tríada género/sexo/poder. En el primer caso, con el deseo de involucrarse sexualmente con personas de su mismo sexo, y en segundo término, con el aspecto (belleza, estatus, nivel de educación), tipo de actos a realizar y posición a ocupar dentro del juego sexual.

Si bien es cierto, en el desarrollo de la sociabilidad homosexual, se esboza una cartografía definida por espacios, lugares y actores cargados de expectativas y formas de comprender el mundo, que terminan por afectar el comportamiento individual y relacionamientos sociales, es la identificación de una naturaleza singular, vinculada a la depredación de cuerpos y gusto por el riesgo, como garantía para asegurar el goce, la que conlleva a asignarle cierto estigma a estas identidades. Según Weeks (1998:40) "La sexualidad se configura mediante la unión de dos ejes esenciales de preocupación: nuestra subjetividad, o sea, quiénes y qué somos, y la sociedad, o sea, el crecimiento, el bienestar, la salud y la prosperidad futuras de la población en su conjunto". 
Con respecto a la homosexualidad como inclinación del deseo de un sujeto hacia otra persona de su mismo sexo, se tiene que el sujeto genera una geografía corporal favorable al placer sexual y la sociabilidad. Es decir, a la forma en que se conduce comportamental el cuerpo dentro de ciertos regímenes, que incluso desde los griegos, ha inducido a los hombres hacia la fabricación de un cuerpo firme, como evidencia del control que ejerce el mercado sobre las personas y del diferendo cultural existente, entre el hombre homosexual tradicional y el hombre gay.

En el caso del hombre gay, la satisfacción del placer involucra un conjunto de vivencias que estructuran su subjetividad, y visibiliza el uso y apropiación de espacios -el gimnasio-, para hacerse un cuerpo ideal, desde una práctica biopolítica $^{4}$ cuyo mecanismo de vigilancia y autovigilancia, descansa en la disposición de los espejos en el lugar. Y si esto no sirve, queda acudir al uso de las cirugías, como servicio auxiliar generado por el sistema capitalista.

Situación ya advertida por McLaren (1991:84) cuando afirma que "nuestros cuerpos son regulados ahora por una fascista economía de los signos justamente porque se los separa ahora tan cabalmente del servicio del cuerpo. En este proceso el cuerpo ha llegado a reducirse a un signo de sí mismo. Se ha abandonado al cuerpo por una mejor versión del cuerpo mismo". La regulación de la sexualidad no parte del control estatal, sino de la autovigilancia de la conducta personal. Es decir, de la regulación-satisfacción de los placeres.

El fin del capitalismo es consolidar un patrón de civilización que permee todos los planos de la existencia social. Para lo cual, se hace necesario constituir circuitos territoriales que configuren vínculos de interacción que afecten la experiencia corporal de los sujetos y los modele. Los modos en que se estructura la sociabilidad de las personas homosexuales en la ciudad, descansa en representaciones culturales de diferencia sexual e integración a la normalidad. "La vida de la ciudad se manifiesta por medio del cambio, de la diferencia y del conflicto" (Borja,2003:27).

La ciudad ahora, es el resultado de un proceso de socialización de fuerzas productivas, que sumado a la desregularización de algunas funciones estatales y la consolidación de los sistemas de consumo individual y colectivo, hacen pensar que en el desarrollo del capitalismo en la ciudad, no solo producen las empresas, sino también los individuos, al desarrollar sus capacidades en dicho proceso. Según Margulis (2002:520) "la ciudad cambia por las acciones
4 Desde Foucault la biopolítica nace como el disciplinamiento y la normalización en la modernidad, y se enfoca en la protección de la vida para regularla. En ese sentido, la "sexualidad" como un modo de experiencia históricamente singular en el cual el sujeto es objetivado para sí mismo y para los otros, a través de ciertos procedimientos precisos de "gobierno", permite ver el punto de contacto entre la tecnología política aplicada a los individuos y las tecnologías que uno mismo desarrolla para conducirse dentro de estos regímenes. Según el estudio que hace Foucault, tanto en Voluntad de saber como en Historia de la sexualidad estas formas de poder se introducen entre los siglos XVII y XIX, y se presentan como la regulación de los cuerpos, la intromisión de la normalización en la sociedad. Tanto, desde una mirada interna vinculada con el saber/poder sobre la vida, como externa, es decir de la vida con sus entornos. 
que en ella se desarrollan y por la articulación material y simbólica de su tiempo y espacio".

\section{Ciudad y sexualidad. La configuración del sujeto y su subjetividad}

bordar el tema de la subjetividad homosexual masculina desde
los relatos de vida implica de una parte advertir que la lectura de
lo social se hace desde la especificidad de los sujetos, el carácter acumulativo de sus experiencias y la conexión que estas tienen con ciertos lugares y espacios. La subjetividad es el resultado de las prácticas que se insertan en el proceso de configuración de un tipo de individuo, para lograr una definición de sí mismo, que dadas las condiciones de espacio y tiempo, al decir de Gallego et al. (2016:185-186) "[...] permiten inferir que se asiste a un periodo de institucionalización de la vida erótica y afectiva en personas con prácticas homoeróticas, tal vez como señal de un proceso político más general. Este proceso instala unos marcos de posibilidad, pero a la vez conlleva a un disciplinamiento que demarca nuevas fronteras de moralidad sexual".

La configuración de las subjetividades se produce en movimiento. Por un lado, desde la relación consigo mismo, y luego, desde la interacción con el otro que me subjetiva. La subjetividad incluye el conocimiento de las formas de construcción específica de los sujetos, dentro de un espacio social predeterminado, y sus implicaciones en el tiempo.

En palabras de Vommaro (2012:68) "Los procesos de subjetivación están situados espacial y temporalmente, y expresan una forma de vida por la cual el individuo deviene sujeto. Estos procesos están conformados por valores, percepciones, sentimientos, afectos, lenguajes, saberes, deseos, concepciones, prácticas y acciones que se inscriben en el cuerpo producido, vivido y experimentado de los sujetos. En tanto acto de ruptura o fractura con lo instituido, la subjetivación implica un movimiento, un desplazamiento, una fuga respecto a la normalización y homogenización que objetiva el poder".

Con respecto a la configuración de la subjetividad homosexual en la ciudad, esta se halla atravesada por elementos de carácter contextual (criminalidad, violencia) y actitudinal, que pueden reducir o aumentar la tensión entre la libertad que otorga el espacio citadino versus el espectro de prácticas sociales y marcos institucionales, que transversalizan la experiencia de los sujetos. 
Esto incluso cuando el aspecto físico, modo de hablar y expresión gestual del sujeto/objeto de deseo apunten a la obtención efectiva de placer sexual.

Siguiendo los argumentos de Foucault, con respecto a las relaciones de poder estas actúan sobre un fondo de diferentes posibilidades de actuación con el fin de intentar "conducir las conductas", y así modelar la configuración de subjetividades mediante un entramado de discursos y técnicas que irían conformando su factibilidad dentro de un medio que es cambiante. "Las identidades homosexuales ilustran la relación entre la restricción y la oportunidad, la necesidad y la libertad, el poder y el placer" (Weeks, 1998:333). Elementos cuyo espectro otorga significancia personal y referencia social al individuo, dentro de los diferentes procesos de socialización a que este tendría acceso.

Según Deleuze (1995:275) "[...] los procesos de producción de subjetividad son las diversas maneras que tienen los individuos y colectividades para constituirse como sujetos: esos procesos solo valen la pena en la medida en que al realizarse, escapen a los poderes dominantes". Es decir, a la aplicación de dispositivos institucionales, o emergencias de tecnologías del yo, que permitan la identificación de los sujetos y organización de sus flujos de vida.

La constitución del homosexual masculino en la ciudad, ha estado dada en términos de una codificación que parte de los circuitos territoriales y redes sociales, donde las fantasías que acerca el uso de las tecnologías de la información y la comunicación, sumado a un mundo de comercio, estructuran la experiencia de los sujetos. Tanto, que desde la lógica mercantil, el varón homosexual citadino, hoy se convierte en objeto de comercio, no solo por su capacidad de consumo, sino también, por la posibilidad que tiene de convertirse en sujeto de placer sexual, al exhibir y en algunos casos vender su cuerpo y compañía a otros hombres en diferentes lugares. Ejemplo de lo anterior, se advierte en el siguiente fragmento:

Llevaba varios días, saliendo en las noches al parque y detallando qué hombres estaban solos. Luego de varios días, decidí acercarme a uno y ofrecerle un café, el cual aceptó sin reparo. Hola, fue su primera palabra seguida de ¿cómo está? Mi respuesta fue contundente, aburrido de tanto man que quiere modelos y no sabe que el mercado local es de feitos. Cuestión a la cual él respondió, yo te quiero a ti bebé para ser amigos y amantes. Nunca antes, nadie había sido tan 
tierno y directo. Sin embargo, para salir de esta situación acudí a preguntar ¿Qué haces en la vida? A lo cual respondió busco empleo y vos. Ya encontré uno. Seguimos conversando, y pronto apareció el placer verbalizado a través de la pregunta ¿Eres vergón? Mi sonrisa se achicó y mis ojos que parecían puestos en él tomaron otro rumbo, el cual se recuperó por la pregunta ¿vives solo? Interrogante, que atiné a responder con pago arriendo y por la hora ya no puedo llevar visitas. (Diálogo 24 de diciembre de 2015. Villavicencio-Plazoleta los Libertadores 8:00 pm).

Conversación donde la búsqueda de placer, reafirmación del rol de género y satisfacción de las fantasías sexuales de corte homoerótico marcan una experiencia subjetiva que reproduce las identificaciones sexuales y relaciones consentidas de subordinación, pero ahora con un aditamento especial, a saber el ejercicio de la prostitución masculina. En la experiencia de sí mismo, como sujeto de una "sexualidad", es indispensable conocer cómo se organiza socialmente el placer, quiénes participan de él y qué otras relaciones se pueden generar con espacios e individuos. Tal y como se desprende del siguiente fragmento de diario de campo:

He ingresado al sauna. Desprendido de todas mis prendas y tan solo cubierto por una toalla y el respaldo de un preservativo. Atisbo dos personas, uno joven y otro más maduro, que han llegado minutos antes al lugar y se disponen a divagar por él, chequeando qué hay y sucede al interior de cada microespacio -baños, celdas, rincones, sala de video, cuarto oscuro-. De pronto, el hombre más maduro, se detiene en la sala de video, está de pie y su cuerpo atlético, llama mi atención. Me acerco, pregunto bobadas e intento rozarlo con mi mano. Consiente la acción y trato de descubrir qué se esconde bajo su toalla. La sorpresa extraña, pese a ser moreno no está tan bien dotado como popularmente se cree. V??? al menos así me dijo que se llamaba, es tímido, sonríe con desconfianza, pero acepta que lo masturbe. Me pide que pare, que mi cadencia lo excita, que no vamos a un cuarto. Acepto, es amable y educado. Sin embargo, me dice que no es gay. Duró 6 años casado y bueno...tú ya sabes. Se recuesta, me pide que repose mi espalda sobre su pecho, cálido y palpitante... me atrapa. Pide entonces, que me gire para masturbarme, besar mi espalda, y rascar mi cuello con su barbilla. Sus besos son violentos, y sus labios parecen ya de gelatina como producto del embriague 
de placer. Me aprieta, susurra... y yo lanzo a decirle que debo irme. Reacciona, me pide que lo espere, que si quiere me invita a su casa, que tengo un pelo lindo, soy chévere, que lo hago reír. Nos vestimos, salimos del lugar, caminamos y me dice que apunte su número, pero no puedo el celular está en el morral, son casi las 10:00 pm y la zona es insegura. Pasa el bus y yo también lo tomo, pero él no es capaz de pagar mi pasaje, de cerrar aquella escena con un fino gesto de coquetería. Llego a la casa, tomo una ducha y descubro las prueba de mis andanzas, un morado que además de doler tiene el tamaño de su propio pene (Diario de campo 09-07-2016).

Ejemplo, en donde el sauna como lugar de interacción socio-sexual, posibilita al sujeto homosexual convertirse en empresario de sí, al disponer su cuerpo hacia una actitud de satisfacción del placer sexual, desprovista de miedos y temores, pero no liberada de prejuicios sociales. Ya que en el fondo, este y su subjetividad, siguen siendo el producto de unos regímenes, cuyas estrategias sociales de disciplinamiento, se aplican sobre el cuerpo y la administración de la vida misma.

La sexualidad, en tanto espacio de producción, registro y consumo de diferentes mercancías, se reconfigura ahora bajo una realidad orgánica, que no solo revela la constitución de una geografía corporal, sino además, la existencia de un tiempo que estructura los relatos de los presentes allí, y hace de la ciudad un contenedor de recursos, para que los sujetos puedan establecer contacto con otros y así definir, un nuevo tipo de actitudes y formas de autoerotismo, que les permita a sus vidas fluir. Al explorar cómo se activa el placer sexual homosexual en la ciudad, se tiene que este posibilita otros procesos en la ciudad, los cuales van desde el tránsito de los cuerpos y el rompimiento de los convencionalismos sociales.

Según Deleuze y Guattari (1985:147), la sexualidad como máquina social "[...] tiene como piezas a los hombres, incluso si se les considera máquinas, y los integra, los interioriza en un modelo institucional a todos los niveles de acción, de la transmisión y de la motricidad". Esto en razón, a que la estructura social es deseo mismo -dominación-.

La subjetividad, como lo bien lo expresara Foucault pasa por un proceso de normalización, y los cuerpos no solo son la materia prima donde se inscribe o asienta el orden social, al disciplinarlos, sino uno de los recursos que lo 
puntualizan, expresan y reproducen. "[...] el sujeto se forma a partir de una serie de procesos y sistemas que no responden a una naturaleza originaria de la subjetividad, sino que obedecen a condiciones históricas, políticas y sociales" (Castro 2008:173). Situaciones que en el capitalismo fomentan la cultura narcisista y hedónica de los individuos, a partir de la propia disposición a asumir una práctica de sí mismo, que ahora se halla colonizada por la configuración de una subjetividad dócil, como producto de la aceleración del tiempo social, y la sublimación del placer como modo de vida. En otras palabras, de "el polvo fugaz que no te compromete y te permite seguir siendo otro" (Pineda, 2014:13).

\section{El placer sexual en la ciudad mercado}

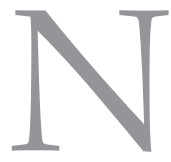

o cabe duda que los cuerpos que asisten a la nocturna de la Plazoleta Los Libertadores, en el centro de Villavicencio como lugar público, se ubican en el adentro y afuera de una actuación, que subvierte las normas sociales preestablecidas, a partir de la activación de un conjunto de prácticas socio-sexuales, que no solo engendra sujetos y cuerpos cargados de placer, sino que a su vez, configuran una subjetividad homosexual fuera del territorio de la normalidad, al ampliar los sentidos y significados que para estos posee el cuerpo en tanto materialidad para el hacer.

Situación, que no solo entraña rupturas y continuidades en lo relativo a las tensiones producidas por la apertura a nuevas formas de búsqueda del placer, al interior de la matriz heteronormativa que caracteriza a la ciudad, sino también, ante una hegemonía fálica que empieza ser cuestionada por no admitir ciertos estilos de vida. Para Foucault, la categoría placer (sexual) se vincula con una experiencia vivida desde el goce corporal indeterminado, dentro de un tiempo no lineal, cuya codificación se da partir de la experiencia misma del sujeto en el aquí y el ahora.

Bajo ese orden de ideas, plantear que el placer es la experiencia corporal surgida a partir de una fantasía sexual, cuyas referencias se ubican a través de diferentes procesos históricos, que conllevan a la construcción de representaciones socioculturales, en torno a sujetos/objetos de deseo y la exploración misma de las fronteras normativas convencionales, de cuenta de la configuración de la subjetividad homosexual en la ciudad, se halla influenciada en gran parte por el carácter esporádico de sus relaciones, la casualidad de sus encuentros y una renovada reflexividad frente a los diferentes modos de vivir el placer sin restricciones. 
Afirmación esta, que no vacila en resaltar al sujeto individual como protagonista del proceso de socialización, además de advertir la presencia de unas coordenadas históricas, que irían a configurar la producción subjetiva de los individuos, desde las interacciones cotidianas. "En la perspectiva sociológica la socialización ha sido entendida como el proceso a través del cual el sujeto internaliza la realidad externa en sus dimensiones natural y social, constituyéndola en realidad subjetiva" (Alvarado y Ospina, 2009:57).

Cuestión que le ha otorgado al placer una connotación negativa, en el sentido de definir a sus protagonistas, como sujetos narcisistas y azuzadores de la disolución entre aquello que se considera normal y patológico, dado el binomio sexo/género, pero que ante la condición capitalista advierte como "lo que más interesa en las tecnologías liberales no es tanto que los sujetos trabajen para satisfacer necesidades básicas (comer, dormir, abrigarse, descansar) y adquirir objetos materiales (cosificados como propiedad), sino que se "capitalicen a sí mismos", es decir que logren "invertir" sus recursos en ámbitos inmateriales como la belleza, el amor, la sexualidad, el conocimiento, la espiritualidad, las buenas maneras, etc., pues tales inversiones contribuyen a aumentar sus posibilidades de movilidad en una "economía abierta de mercado" (CastroGómez,2010:51).

La captura que hace el capital del sujeto, termina por constituirlo como un organismo, que a su vez es producido por la domesticación de la vida y la forma en que el capital mismo establece modos y vivencias del placer (homosexual). El sujeto se configura desde la experiencia y prácticas que organizan su cuerpo. Lo que sugiere, que la estructuración de la vida misma sucede por la intervención que se hace desde las instituciones creadas en el ámbito de lo social y las prácticas sociales agenciadas por determinados sujetos en un tiempo y espacio históricamente dados.

Las instituciones, de acuerdo con North (1993:13) "Son las reglas del juego en una sociedad o, más formalmente, los constreñimientos u obligaciones creadas por los humanos que le dan forma a la interacción humana". Mientras que las prácticas sociales al decir de Abric (2001:195) "[...] son sistemas de acción socialmente estructurados e instituidos en relación con papeles".

Razón, para que la apuesta de este apartado esté enmarcada en la deriva espacial, en los flujos de información que ofrecen los microespacios y visibiliza rostros, palabras, historias sobre la constitución subjetiva en la ciudad. Si bien 
es cierto, la ciudad muestra disposición a aceptar la existencia de discotecas, cafés y restaurantes con orientación gay, esta desconoce a la homosexualidad en tanto práctica sexual, como algo legítimo desde una perspectiva moral. Lo que lleva a asumir, que aunque son múltiples los escenarios, discursos y prácticas que se ofrecen para la configuración del sujeto homosexual en la ciudad, estos no son percibidos por la ciudadanía como dinámicos y vinculados a otros entramados socioculturales.

Con respecto, a la configuración de las subjetividades homosexuales en la ciudad, se tiene que estas, han emergido como producto del ofrecimiento de diferentes ámbitos de identificación que han posibilitado en los sujetos, un momento personal para señalar su mismidad y continuidad en el conjunto de las interacciones sociales. Además, de revelar la forma en que algunos de estos, reconfiguran el paisaje citadino, a partir de las prácticas de placer que agencian. Como se muestra, a través del siguiente fragmento observacional:

Día de partido (11-06-2016/8:40 pm), llueve en la tarde y la noche está movida por una brisa fría pero tolerante. El parque central está casi vacío, y a lo lejos se distinguen 4 grupos (indigentes, bebedores de tinto, y 2 grupos de hombres. 9-15 pm). Luego de rodear el parque, me ubico de espaldas a la catedral y frente a la fuente. El grupo de jóvenes, ha empezado a realizar recorridos en varias direcciones, que terminan por definir un círculo completo. De pronto toman una sola ruta, y sin más que hacer, decido seguirlos con prudencia, para saber dónde terminarán. Los acompaño hasta las 10:00 pm, luego que deciden adentrarse en un matorral oscurecido por la sombra de dos ceibas. 10:15, Ninguno de los chicos sale y entonces marcho hacia mi casa. (Fragmento diario de campo Plazoleta Los Libertadores, Villavicencio)

El espacio social citadino es un escenario de relaciones de poder, en donde la existencia de grupos diferenciados muestra como estos a la vez, también realizan taxonomías de sus integrantes o subgrupos, en razón a criterios tales como acceso a la tecnología, apertura a la globalización, tipo de prácticas sexuales, señales físicas, edad y lugar de residencia. Factores que no solo trasciende la fuerza de las construcciones históricas, sino de readaptación para generar líneas de diferenciación entre miembros de un mismo colectivo, y así ofrecer elementos para una experiencia social menos homogénea. 
Con respecto a la producción de subjetividades sexuales, se tiene que:

La identidad homosexual, por ejemplo, es un accidente sistemático producido por la maquinaria heterosexual, y estigmatizada como antinatural, anormal y abyecta en beneficio de la estabilidad de las prácticas de producción de lo natural. Esta maquinaria sexo-prostética es relativamente reciente y, de hecho, contemporánea de la invención de la máquina capitalista y de la producción industrial del objeto. Por primera vez en 1868, las instituciones médico-legales identificarán este accidente «contranatura» como estructuralmente amenazante para la estabilidad del sistema de producción de los sexos oponiendo la perversión (que en ese momento incluye todas las formas noreproductivas de la sexualidad, del fetichismo al lesbianismo pasando por el sexo oral) a la normalidad heterosexual (Preciado, 2011:22).

La configuración de la identidad sexual, se ha producido históricamente desde la idea de lo colectivo-institucional, descuidando las vivencias y experiencias particulares de cada sujeto. Lo que lleva a plantear, que la ciudad no sería tan solo un espacio físico y geográfico que contiene y determina las acciones de los sujetos (homosexuales), sino también un escenario de socialización, que permite a las personas incorporar modos de ser y estar en y con el espacio, dado el sentido de socialmente construido que este guarda.

Con respecto a la forma en que los varones homosexuales de Villavicencio generan y buscan placer sexual, se tiene que estos ponen de manifiesto su intención sexual, establecen filtros frente al acercamiento de otros hombres y precisan del tipo de prácticas a desarrollar, tal y como se puede observar, desde lo consignado en el perfil de un miembro del portal www.manhunt.net:

A??? es una persona de 23 años, serio, reservado, culto, educado, estudioso y simpático. Esto se trata de ser correspondientes; si hay gusto o interés primero lo primero "liberar fotos". Busco como primera instancia que me conozcan y conocer, observar y que me observen.... y consecutivamente que hablemos un buen rato y que nos demos confianza para que de esa manera expresemos de una manera diferente ese gusto. En el sexo me gusta que me disfruten y disfrutar, que me toquen y tocar, que me exciten y excitar. De un sexo suave a un sexo duro... considero que el sexo no es culiar por culiar si no vivir intensamente ese momento y sobre todo a la persona. Es 
una gran mentira cerrarse a la oportunidad de encontrar a alguien especial, simplemente uno no escoge de quién enamorarse si no es esa atracción y sentimiento que te llega por alguien. Busco conocer gente con una personalidad sana en todo sentido, seria, reservada, educada, estudiosa, sencilla, trabajadora, cumplida, respetuosa, masculina y que busque un buen sexo responsable y abiertos a posibilidades. Abrazos A???

Descripción que deja ver cómo aunque se pide placer, no todo sirve. Si bien es cierto, existe una codificación de las conductas y normas sexuales cuya base descansa en los órganos sexuales opuestos y que logran acoplarse de mejor manera, Preciado (2011:23) dirá que "La exclusión de ciertas relaciones entre géneros y sexos, así como la designación de ciertas partes del cuerpo como no-sexuales, más particularmente el ano; como Deleuze y Guattari han señalado «el primero de todos los órganos en ser privatizado, colocado fuera del campo social» son las operaciones básicas de la fijación que naturaliza las prácticas que reconocemos como sexuales".

Asunto, que abre la discusión frente a como el placer descubre esa satisfacción al explorar el cuerpo, pero que una vez satisfecha se torna en desencanto, pues el placer es efímero. No obstante, el placer cumple una tarea positiva a saber, la de deconstruir la imagen del contrato sexual. Al poder utilizar el ano, no solo es posible concebir relaciones sociales de otro modo, sino que al ya no estar privado, sino abierto al deseo, este supera las dicotomías clásicas entre individuo-sociedad, público-privado, recuperando así su carácter productivo. El placer anal, no se interpreta, se muestra en los claroscuros de la noche, en la liberación del cuerpo como producto de los vapores aromáticos en los cuartos de sauna, o a través de la lente de la cámara en las salas de chat. Hablo de conexiones no exclusivas, de prácticas para constituirse a sí mismo en sujeto.

Cuando se habla del placer, se hace mención a la sensibilidad práctica y polimórfica que se desprende de la constitución individual y que configurará los acoples en los cuales los comportamientos sexuales de un individuo, solo tendrán sentido si se hallan situados en el curso de su vida individual y los trayectos de interacción con otras personas. La dinámica biográfica con respecto al placer, no solo transita entre lo íntimo, semipúblico y público, sino que ahora, ella misma debe atender a los diferentes eventos, procesos y aprendizajes donde el sujeto participa, a través de sus devenires homosexuales. 
Por ello, analizar como esos encuentros ocasionales surgidos ante la disposición de diferentes lugares al interior de la ciudad despiertan el interés del otro, pero luego de su partida y consumado el acto sexual, revelan como este último, se ha convertido en algo tan fácil de alcanzar que los homosexuales "corren el peligro de aburrirse rápidamente, generando toda clase de esfuerzos para innovar y para crear variaciones que refuercen el placer del acto" (Foucault, 1985:31). Lleve a postular, que el total de la energía e imaginación, se orientan a intensificar el acto sexual, a través del desarrollo de nuevos tipos de prácticas sexuales, en las cuales se erotiza el cuerpo y las relaciones, como posibilidad interna para alcanzar una experiencia sexual plena y fluida.

Si bien es cierto que en algunas ocasiones la ansiedad expresada por parte de algunos homosexuales ante el ofrecimiento de otros cuerpos masculinos, en algunos lugares de la ciudad deja ver su apetito sexual, también es verdad que otros más, abrigan la idea de una vida sencilla, donde el solo vivir sea suficiente. La búsqueda de placer en la ciudad, ha favorecido la experimentación de una excesiva serie de riesgos y pérdidas, que dada las dinámicas del mercado espectáculo, han terminado por definir una narrativa propia de sus vidas y de la ciudad misma.

Por esa razón, que observar como ciertos lugares y zonas de la ciudad, pero también la noche permiten el acceso al sexo y a otras experiencias placenteras del cuerpo, revele como la seguridad física y emocional también se ponen a prueba. Para el caso de los homosexuales, todo inicia con una mirada que requiere complicidad entre las partes, pero que también puede estar complementada, por persecución, exposición y contacto corporal, tal y como lo menciona Tewksbury (1996 citado por Langarita Adiego, J. 2014).

Por tal motivo, insistir que es desde los tránsitos y recorridos que adelantan los individuos a través de la ciudad, que se hace posible advertir un sistema de lenguaje no verbal y más simbólico, frente a las diferentes técnicas de negociación sexual para alcanzar el acto, de cuenta aquí, de cómo los espacios son construidos socialmente, y definidos en razón a los recursos o capacidades que ofrecen para la gestión del goce. Un goce, que inicia con el merodeo y el intercambio de miradas, como potencia incrementadora de las expectativas sexuales que cada sujeto pretende realizar, dada la disposición de otros cuerpos y la relación con factores como tiempo, dinero, lugar y tipo de práctica(s) sexual(es) a ejecutar. 
Ahora el sujeto homosexual es producto de un modo de objetivación que dada la existencia de la ciudad-mercado, ve sus prácticas socio-sexuales como el resultado de la aplicación normativa y de formación de verdad, no solo sobre su persona, sino también frente a la comprensión que tiene del placer.

\section{Conclusiones}

T a ciudad como la sexualidad, son formas de institucionalización que estabilizan y recrean ciertas categorías identitarias en el tiempo. Por tal I motivo, acercarse desde una actitud reflexiva a los efectos de poder que dichos marcos producen en la constitución de los sujetos homosexuales y sus prácticas, involucra ratificar la idea de que la sexualidad es un constructo social, que dentro de la cultura occidental moderna ha servido como escenario para ejercer control y generar discursos de verdad sobre los individuos y la administración de sus vidas.

Incluso frente a las prácticas sexuales entre personas del mismo sexo, el dispositivo de sexualidad las define e identifica bajo una condición diferenciada, que marca una subjetividad, además de ejercer una función de constitución de saberes y normas, que limitan el libre fluir de tales individuos y su posibilidad de transformarse en sujetos. Esto en virtud, a que el individuo deviene en sujeto, dada su vinculación espacio-temporal. Tanto así, que desde la perspectiva de Castro-Gómez (2010:212) "[...] lo que se considera sustancialmente personal no es otra cosa que un cierto tipo de sensación que se efectúa a través de un particular poder que ya no opera normalizando la subjetividad mediante el confinamiento de los individuos, sino modulando sus deseos en espacios abiertos".

La experiencia identitaria-subjetiva de los sujetos, se halla mediada por el conjunto de relaciones, que los atraviesan y ofrecen un conocimiento de sí mismo, que en la condición capitalista se halla caracterizada por hacerse "empresario de sí mismo". Iniciativa, que visibiliza el doble movimiento del devenir subjetivo, es decir lo instituido que hay en él, junto a la capacidad de agencia para luchar contra aquello que lo limita.

En la condición capitalista-neoliberal, el cuerpo-sujeto es organizado en un dispositivo-persona, que subjetiva no solo su fisiología, sensibilidad y potencia vital, sino que lo convierte en útil y productivo para el sistema, desde el apocamiento de las fuerzas que constituyen su diversidad. Ahora, el sujeto homosexual, se unifica como empresario de sí, y vive bajo una continua relación con los excesos, el rendimiento y la competencia. 
Bajo ese orden de ideas, afirmar que la subjetividad es producto de la socialización a la que no escapa ningún individuo, haya sido el pretexto para acercarse a la comprensión de la producción subjetiva homosexual en la ciudad, desde sus técnicas de gestión y dispositivos de control. Si de algo, no hay duda es que el sujeto homosexual bajo el contexto capital, vive en los márgenes de su libertad, en el goce y la competencia por constituirse en el actor de su propia vida, y gestar desde allí un hábitat, que supere lo precario, líquido y desconocido que para él mismo constituye el tiempo actual.

Si se atiende a que el fin último del capitalismo es la producción de un sujeto nuevo, un sujeto homogenizado a causa de la lógica empresarial, competitiva, y tecno-comunicacional, que reduce su miedo a la soledad y favorece la proximidad social, cabe preguntar sí en dicha relación existe la posibilidad para constituir referentes simbólicos que le permitan al individuo elaborar una política de resistencia a los dispositivos que amarran su cuerpo y subjetividad. Esto en virtud, a que en la estandarización de la subjetividad, la imagen y potencia vital de los sujetos, es considerada un recurso valioso, en la activación del placer y las prácticas de consumo, en que transita la experiencia sexo-erótica y porque no afectiva, de tale sujetos.

\section{REFERENCIAS BIBLIOGRÁFICAS}

Abric, J. (2001). Prácticas sociales y representaciones sociales. México: Ediciones Coyoacán.

Alvarado, S. \& Ospina, C. (2009). Contexto teórico para la reflexión sobre socialización política. En Tonon, G (Comp) Comunidad, participación y socialización política. Buenos Aires: Espacio Editorial.

Borja, J. (2003). La ciudad conquistada. Madrid: Alianza Editorial.

Brigeiro, M.(2012). La investigación sobre sexualidad en Colombia (1990-2004): balance bibliográfico. Bogotá: Universidad Nacional de Colombia. Facultad de Ciencias Humanas. Escuela de Género: Río de Janeiro: Centro Latinoamericano en Sexualidad y Derechos Humanos.

Bustamante, W. (2004). Invisibles en Antioquia, 1886-1936. Una arqueología de los discursos sobre la homosexualidad. Medellín: La Carreta. 11.

Bustamante, W. (2008). Homofobia y agresiones verbales. La sanción por transgredir la masculinidad hegemónica. Colombia, 1936-1980. Medellín: Todográficas.

Butler, J. (2005). Lenguaje, poder e identidad. Madrid, España: Síntesis.

Castro, E. (2008). Foucault y el cuidado de la libertad. Ética para un rostro de arena. Santiago de Chile: Editorial LOM. 
Castro-Gómez, S. (2010). Historia de la gubernamentalidad, razón de Estado, liberalismo y neoliberalismo en Michel Foucault. Bogotá: Siglo del Hombre.

Deleuze, G., \& Guattari, F. (1985). El anti Edipo. Capitalismo y esquizofrenia. Barcelona: Editorial Paidós.

Deleuze, G. (1995). Conversaciones 1972-1990. Valencia: Pre Textos.

Foucault, M. (1985). Opción sexual y actos sexuales: una entrevista con Michel Foucault. En: Homosexualidad, Literatura y Política. Madrid: Alianza Editorial.

Foucault, Michael. (2010). Tecnologías del yo y textos afines. Barcelona: Paidós-Ibérica.

García, C. (2012). Subjetividad y género: entre lo sustancial y lo efímero. Revista Latinoamericana de Ciencias Sociales, Niñez y Juventud. Manizales: Editorial CINDE.

Gallego, G.; Giraldo, S.; Jaramillo, C.P. \& Vasco, J.F. (2016). Homoerotismo en hombres y mujeres en el eje cafetero colombiano: una interpretaciòn desde el enfoque biográfico. Rev. Colomb. Soc. 39 (1), pp. 167-189.

Gil, F. (2013). Fronteras morales y políticas sexuales: apuntes sobre 'la política LGBT' y el deseo del Estado. Sexualidad, Salud y Sociedad - Revista Latinoamericana. No. 12, pp. 43-68.

Hard, M. \& Negri, A. (2000). Imperio. Cambridge, Massachussets, Harvard University Press, Edición electrónica.Traducción de Eduardo Sadier.

Langarita Adiego, J. (2014). Rituales de interacción sexual entre hombres. Una propuesta de análisis del discurso y de la práctica del sexo anónimo. Gazeta de Antropología, 30 (3). Recuperado de http://www.gazeta-antropologia.es/?p=4613

Mclaren, P. (1991). Pedagogía crítica, resistencia cultural y la producción del deseo. Buenos Aires: Editorial Aique.

Margulis, M. (2002). "La ciudad y sus signos". En: Estudios Sociológicos, Vol. XX, No. 3, pp 515-536.

North, D. (1993). Instituciones, cambio social y desempeño económico. México: Fondo de Cultura Económica.

Pacheco, L. (2005). Territorio y ciudad: la construcción de la subjetividad social. En: Revista Territorios. No. 14, pp. 161-171.

Pineda, R. (2014). Cuerpos obscenos, cuerpos transeúntes, cuerpos gozados. Masculinidades en las penumbras de las salas X de Medellín. Tesis de Maestría en Estudios Socioespaciales. Instituto de Estudios Regionales. Universidad de Antioquia.

Preciado, B. (2011). Manifiesto contrasexual. Barcelona: Editorial Anagrama. Traducción de Julio Díaz y Carolina Meloni. 
Segura, J.M. (2008). Identidades homosexuales y ciudad. Marginados negociando pactos de silencio. En: Prospectiva-Revista de trabajo social e intervención social, No. 13, pp. 149-172.

Segura, J.M. (2014). Diversidad sexual en el municipio de Villavicencio: aportes para una reflexión gubernamental. Revista Eleuthera, 10, pp.13-37.

Segura. J.M. (2015). ¿Dime con quién andas y te diré quién eres? Sexualidad, violencia y vida cotidiana en Puerto López. En: Virajes. Revista de Antropología y Sociología (17) 2, pp. 79-94.

Tewksbury, R. (1996). Cruising for Sex in Public Places: The Structure and Language of Men's Hidden, Erotic Worlds., Deviant Behavior, no 17 (1): 1-19. DOI: 10.1080/01639625.1996.9968012

Vommaro, P. (2012). Los procesos de subjetivación y la construcción territorial: un acercamiento desde experiencias de organizaciones sociales en Buenos Aires. En: Subjetividades políticas: desafíos y debates latinoamericanos (pp. 63-77). Bogotá: Universidad Distrital Francisco José de Caldas.

Weeks, J. (1998). Sexualidad. México: Paidós-UNAM. Traducción Mónica Mansur.

Weeks, J. (1998). La construcción de las identidades genéricas y sexuales. La naturaleza problemática de las identidades. En: Sexualidades en México. Algunas aproximaciones desde la perspectiva de las ciencias sociales (pp. 199-222). México: Colegio de México. 